\title{
The Analysis on Method of Value for the Environment
}

\author{
Peng CUI \\ School of Business Management, Tonghua Normal University, China
}

KEYWORD: value for the environment, Classifying valuation methods, Stated preference methods, Revealed preference methods, economic valuation

\begin{abstract}
In this paper we explore how we can move from the general concepts to the actual estimates of compensation required by the courts. A series of special techniques has been developed to value the benefits from environmental improvement or, conversely, to value the damage done by environmental degradation. Special techniques were necessary because most of the normal valuation techniques that have been used over the years cannot be applied to environmental resources. Benefit-cost analysis requires the monetization of all relevant benefits and costs of a proposed policy or project, not merely those where the values can be derived from market transactions As such, it is also important to monetize those environmental goods and services that are not traded in any market. Even more difficult to grapple with are those nonmarket benefits associated with passive-use or nonuse value, topics explored below.
\end{abstract}

\section{WHY VALUE THE ENVIRONMENT?}

Many federal agencies require benefit-cost analysis for decision making. Ideally, the goal is to choose the most economically desirable projects, given limited budgets. A 1982 amendment to the Endangered Species Act, for example, required benefit-cost analysis for the listing of a species. This requirement was subsequently relaxed, however, due to a lack of defensible benefits measurements. Estimation of benefits and costs is also used for natural resources damage assessments, such as for oil spills. The Federal Energy and Regulatory Commission (FERC) requires benefit-cost analysis for dam relicensing applications. These analyses, however, frequently fail to incorporate important nonmarket values associated with rivers. Ifthe analysis does not include all the appropriate values, the results will be flawed. Have we made progress?[1-5]

Pollination is one example of a valuable ecosystem service with multiple benefits, including nonmarket impacts such as aiding in genetic diversity, ecosystem resilience and nutrient cycling, as well as direct economic impacts of increasing the productivity of agricultural crops. Many agricultural crops rely on bee pollination.

Economists have decomposed the total economic value conferred by resources into three main components: (1) use value, (2) option value, and (3) nonuse value. Use value reflects the direct use of the environmental resource. Examples include fish harvested from the sea, timber harvested from the forest, water extracted froma stream for irrigation, even the scenic beauty conferred by a natural vista. If you used one of your senses to experience the resource-sight, sound, touch, taste, or smell-then you have used the resource. Some of these uses are called passive-use valuesor nonconsumptive use valuesif the resource is not actually used up (consumed) in the process of experiencing it. Pollution can cause a loss of use value, such as when air pollution increases the vulnerability to illness, an oil spill adversely affects a fishery, or when smog enshrouds a scenic vista. A second category of value, the option value, reflects the value people place on a future ability to use the environment. Option value reflects the willingness to pay to preserve the option to use the environment in the future even if one is not currently using it. Whereas use value reflects the value derived from current use, option value reflects the desire to preserve the potential for possible future use. Are you planning to go to Yellowstone National Park next summer? Perhaps not, but would you like to preserve the option to go someday? The third and final category of value, nonuse value, reflects the common observation that people are more than willing to pay for improving or preserving resources that they will never use. One type of nonuse values is a bequest value. Bequest value is the willingness to pay to ensure a resource is available for your children and grandchildren. A second type of nonuse value, a pure nonuse value, is called existence value. Existence value is measured by the willingness to pay to ensure that a resource continues to exist in 
the absence of any interest in future use. The term existence value was coined by economist John Krutilla in his now-famous quote, "There are many persons who obtain satisfaction from mere knowledge that part of wilderness North America remains even though they would be appalled by the prospect of being exposed to it."

\section{CLASSIFYING VALUATION METHODS}

Typically, the researcher's goal is to estimate the total willingness to pay for the good or service in question. This is the area under the demand curve up to the quantity consumed. For a market good, this calculation is relatively straightforward. However, nonmarket goods and services, the focus of this paper, require the estimation of willingness to pay either through examining behavior, drawing inferences from the demand for related goods, or through responses to surveys. And, as highlighted above, capturing all components of value is challenging. This section will provide a brief overview of some of the methods available to estimate these values and to convey some sense of the range of possibilities and how they are related. Subsequent sections will provide more specific information about how they are actually used.

Valuation Methods. Valuation methods can be separated into two broad categories: stated preference and revealed preference methods. Each of these broad categories of methods includes both indirect and direct techniques. The possibilities are presented in Table 1. Revealed preference methods are those that are based on actual observable choices that allow resource values to be directly inferred from those choices. For example, in calculating how much local fishermen lost from the oil spill, the revealed preference method might calculate how much the catch declined and the resulting diminished value of the catch. In this case, prices are directly observable, and their use allows the direct calculation of the loss in value. Or, more indirectly, in calculating the value of an occupational environmental risk (such as some exposure to a substance that could pose some health risk), we might examine the differences in wages across industries in which workers take on different levels of risk. Compare this with the direct stated preference case that might be used when the value is not directly observable. In Table 1, for example, the nonuse value of the Northern Spotted Owl was not directly observable. Hence, the authors attempted to derive this value by using a survey that attempted to elicit the respondents' willingness to pay (their "stated preference") for the preservation of the species.

Table1 Economic Methods for Measuring Environmental and Resource Values

\begin{tabular}{|c|c|c|}
\hline $\begin{array}{c}\text { Method } \\
\text { s }\end{array}$ & $\begin{array}{c}\text { Revealed } \\
\text { Preference }\end{array}$ & Stated Preference \\
\hline Direct & $\begin{array}{c}\text { Market Price } \\
\text { Simulated Markets }\end{array}$ & $\begin{array}{l}\text { Contingent } \\
\text { Valuation }\end{array}$ \\
\hline Indirect & $\begin{array}{c}\text { Travel Cost } \\
\text { Hedonic Property } \\
\text { Values } \\
\text { Hedonic Wage } \\
\text { Values } \\
\text { Avoidance } \\
\text { Expenditures }\end{array}$ & $\begin{array}{c}\text { Attribute-Based } \\
\text { Models } \\
\text { Conjoint Analysis } \\
\text { Choice Experiments } \\
\text { Contingent Ranking }\end{array}$ \\
\hline & $\begin{array}{l}\text { fied by the } \\
\text { Carson, }\end{array}$ & from Mitchell and \\
\hline
\end{tabular}

\section{STATED PREFERENCE METHODS}

Stated preference methods use survey techniques to elicit willingness to pay for a marginal improvement or for avoiding a marginal loss. The most direct approach, called contingent valuation, provides a means of deriving values that cannot be obtained in more traditional ways. The simplest version of this approach merely asks respondents what value they would place on an environmental change (such as the loss of a wetlands or increased exposure to pollution) or on preserving the resource in its current state. Alternative versions ask a "yes" or "no" question such as whether or not the respondent would pay $\$ X$ to prevent the change or preserve the species. The 
answers reveal either an upper bound (in the case of a "no" answer) or a lower bound (in the case of a "yes" answer). This survey approach creates a hypothetical market and asks respondents to consider a willingness-to-pay question contingenton the existence of this market. The major concern with the use of the contingent valuation method has been the potential for survey respondents to give biased answers. Five types of potential bias have been the focus of a large amount of research: (1) strategic bias, (2) information bias, (3) starting-point bias, (4) hypothetical bias, and (5) the observed discrepancy between willingness to pay (WTP) and willingness to accept (WTA). Strategic bias arises when the respondent provides a biased answer in order to influence a particular outcome. If a decision to preserve a stretch of river for fishing, for example, depends on whether or not the survey produces a sufficiently large value for fishing, the respondents who enjoy fishing may be tempted to provide an answer that ensures a high value, rather than the lower value that reflects their true valuation. Information bias may arise whenever respondents are forced to value attributes with which they have little or no experience. For example, the valuation by a recreationist of a loss in water quality in one body of water may be based on the ease of substituting recreation on another body of water. If the respondent has no experience using the second body of water, the valuation could be based on an entirely false perception. Consider another example. Visual aides have been shown to reduce uncertainty and unfamiliarity with the good or service being valued. Labao et al. (2008) found that colored photographs, as opposed to black-and-white photographs, influence respondent willingness to pay for the Philippine Eagle. The colored photographs resulted in a higher willingness to pay than blackand-white photos. Why? The authors suggest that the higher willingness to pay could be explained by photographs in color simply providing more information or by "enhancing respondents' ability to assimilate information." In any case, the nature of the visual aide seems important for revealing preferences.

Exhibiting the greatest sensitivity to the starting point. Hypothetical bias can enter the picture because the respondent is being confronted by a contrived, rather than an actual, set of choices. Since he or she will not actually have to pay the estimated value, the respondent may treat the survey casually, providing ill-considered answers. One early survey (Hanemann, 1994) found ten studies that directly compared willingness-to-pay estimates derived from surveys with actual expenditures. Although some of the studies found that the willingness-to-pay estimates derived from surveys exceeded actual expenditures, the majority of those found that the differences were not statistically significant.7 More recently, Ehmke, Lusk, and List (2008) tested whether hypothetical bias depends on location and/or culture. In a study based on student experiments in China, France, Indiana, Kansas, and Niger, they found significant differences in bias across locations. Given that policy-makers frequently rely on existing benefits estimates when making decisions on other locations, this finding should not be taken lightly. The strengths and weaknesses of using estimates derived in one setting to infer benefits in another, a technique known as benefit transfer, are discussed below. Increasingly, environmental economists are using these types of experiments to try to determine the severity of some of these biases as well as to learn how to reduce bias. Some of these experiments are conducted in a laboratory setting, such as a computer lab or a classroom designed for this purpose. In one such experiment on voluntary provision of public goods (donations), Landry et al. (2006) found that for door-to-door interviews[6-10], an increase in physical attractiveness of the interviewer led to sizable increases in giving. Interestingly, physical attractiveness also led to increases in response rates, particularly by male households. The final source of bias addresses observed gaps between two supposedly closely related conceptswillingness-to-pay and willingness-to-accept compensation. Respondents to contingent valuation surveys tend to report much higher values when asked for their willingness to accept compensation for a specified loss of some good or service than if asked for their willingness to pay for a specified increase of that same good or service. Economic theory suggests the two should be equal. Debate 4.1explores some of the reasons offered for the difference.

Sometimes more than one of these techniques may be used simultaneously. In some cases using multiple techniques is necessary to capture the total economic value; in other cases it may be used to provide independent estimates of the value being sought as a check on the reliability of the estimate. 


\section{REVEALED PREFERENCE METHODS}

Revealed preference methods are "observable" because they involve actual behavior and "indirect" because they infer a value rather than estimate it directly. Suppose, for example, a particular sport fishery is being threatened by pollution, and one of the damages caused by that pollution is a reduction in sportfishing. How is this loss to be valued when access to the fishery is free?

One way to derive this loss is through travel costmethods. Travel cost methods may infer the value of a recreational resource (such as a sport fishery, a park, or a wildlife preserve where visitors hunt with a camera) by using information on how much the visitors spent in getting to the site to construct a demand curve for willingness to pay for a "visitor day." Freeman (2003) identifies two variants of this approach. In the first, analysts examine the number of trips visitors make to a site. In the second, the analysts examine whether people decide to visit a site and, if so, which site. This second variant includes using a special class of models, known as random utility models, to value quality changes. The first variant allows the construction of a travel cost demand function. The value of the flow of services from that site is the area under the estimated demand curve for those services or for access to the site, aggregated over all who visit the site. The second variant allows the analysis of how specific site characteristics influence choice and, therefore, indirectly how valuable those characteristics are. Knowledge of how the value of each site varies with respect to its characteristics allows the analyst to value how degradation of those characteristics (e.g., from pollution) would lower the value of the site. Travel cost models have been used to value beach closures during oil spills, fish consumption advisories, and the cost of development that has eliminateda recreation area. The methodology for both variants is detailed in

Two other indirect observable methods are known as the hedonic property value and hedonic wage approaches. They share the characteristic that they use a statistical technique, known as multiple regression analysis, to "tease out" the environmental component of value in a related market. For example, it is possible to discover that, all other things being equal, property values are lower in polluted neighborhoods than in clean neighborhoods.

\section{USING GEOGRAPHIC INFORMATION SYSTEMS FOR ECONOMIC VALUATION}

Geographic Information Systems (GIS) are computerized mapping models and analysis tools. A GIS map is made up of layers such that many variables can be visualized simultaneously using overlays. Use of GIS to inform economic analysis isarelatively recent addition to the economist's tool kit. GIS offers a powerful collection of tools for depicting and examining spatial relationships. Most simply, GIS can be used to produce compelling graphics that communicate the spatial structure of data and analytic results with a force and clarity otherwise impossible. But the technology's real value lies in the potential it brings to ask novel questions and enrich our understanding of social and economic processes by explicitly considering their spatial structure. Models that address environmental externalities have, almost by definition, a strong spatial component. One study (Bateman et al., 2002) examines the contributions of GIS in incorporating spatial dimensions into economic analysis, including benefit-cost analysis. Another study (Clapp et al., 1997) discusses the potential contributions GIS can make for urban and real estate economics.

\section{CONCLUSION}

In this paper we have examined the most prominent, but certainly not the only techniques available to supply policy-makers with the information needed to implement efficient policy. Finding the total economic value of the service flows requires estimating three components of value: (1) use value, (2) option value, and (3) nonuse or passive-use value.Our review of these various techniques included direct observation, contingent valuation, contingent choice experiments, travel cost, hedonic property and wage studies, and averting or defensive expenditures. When time or funding precludes original research, benefits transfer or meta-analysis provides alternate methods for estimation of values. Examples of actual studies using these techniques were presented. 


\section{ACKNOWLEDGMENT}

This research was financially supported by the Project of Education Department of Jilin Province (Grant No.2014388)

\section{REFERENCES}

[1] Yingying Huang, Wenjian Shi, Caihong Zhang et al.. Diazo-coupling spectrophotometric determination of nitrogen oxides in the air[J]. Atmospheric Pollution Research, 2015.

[2] Luther Smith, Shaibal Mukerjee, Kasey Kovalcik et al.. Near-road measurements for nitrogen dioxide and its association with traffic exposure zones[J]. Atmospheric Pollution Research, 2015, $6(6)$.

[3] Krzysztof Czerwionka. Influence of dissolved organic nitrogen on surface waters[J]. Oceanologia, 2015.

[4] Rania A.B. Saad, Peter Kuschk, Arndt Wiessner et al.. Role of plants in nitrogen and sulfur transformations in floating hydroponic root mats: A comparison of two helophytes[J]. Journal of Environmental Management, 2016.

[5] Dayana Milena Agudelo-Castaneda, Elba Calesso Teixeira, Felipe Norte Pereira. Time-series analysis of surface ozone and nitrogen oxides concentrations in an urban area at Brazil[J]. Atmospheric Pollution Research, 2014, 5(3).

[6] Melissa R. Michelson, Getting Out the Latino Vote: How Door-to-Door Canvassing Influences Voter Turnout in Rural Central California[J]. Political Behavior, 2003, Vol.25 (3).

[7] Y.J. Li, Q. Dai, Y. Zhang et al.. Design and analysis of an electromagnetic turnout for the superconducting Maglev system[J]. Physica C: Superconductivity and its applications, 2016, 528.

[8] Jens C.O. Nielsen, Björn A. Pålsson, Peter T. Torstensson. Switch panel design based on simulation of accumulated rail damage in a railway turnout[J]. Wear, 2016.

[9] Ping Wang, Jingmang Xu, Kaize Xie et al.. Numerical simulation of rail profiles evolution in the switch panel of a railway turnout[J]. Wear, 2016.

[10] Camci Fatih, Eker Omer Faruk, Baskan Saim et al.. Comparison of sensors and methodologies for effective prognostics on railway turnout systems[J]. Proceedings of the Institution of Mechanical Engineers, Part F: Journal of Rail and Rapid Transit, 2016, 230(1). 